\title{
Motivating preservice physics teachers to low-socioeconomic status schools
}

\author{
Xiaoming Zhai ${ }^{1,{ }^{*}}$ Barbara Schneider ${ }^{2}{ }^{2}$ and Joseph Krajcik ${ }^{2,3}$ \\ ${ }^{1}$ Department of Mathematics and Science Education, University of Georgia, Athens, Georgia 30602, USA \\ ${ }^{2}$ College of Education, Michigan State University, East Lansing, Michigan 48824, USA \\ ${ }^{3}$ CREATE for STEM Institute, Michigan State University, East Lansing, Michigan 48824, USA
}

(Received 27 May 2020; accepted 3 September 2020; published 19 October 2020)

\begin{abstract}
Recruiting high-quality physics teachers for low-socioeconomic status (SES) schools is essential for ensuring equity but is challenging globally. China launched a four-year program to meet the challenge by providing free education and stipends and promising a career position to attract high-performance secondary graduates, while using a contract to constrain participants to serve 10 years as K-12 science, technology, engineering, and mathematics teachers, with the first two years in low-SES rural schools. This program had recruited more than 101000 preservice teachers in all academic areas, and more than $90 \%$ went to teach in low-SES rural schools. In this paper, we clustered participant physics teachers according to their motivation to serve low-SES schools and commented that the use of the "carrot and stick" policy has both positive and negative effects. On one side, the preservice teachers who had higher motivation for serving low-SES communities increased their motivation significantly during the four-year professional learning; on the other side, a portion of teachers who had lower initial motivation failed to develop adequate motivation. Even though the carrot and stick model seems to achieve its established goal, we argue that the "carrot-stick" policy may need adjustment and that the implications from this preservice teacher policy are useful for developing policies in other countries.
\end{abstract}

DOI: 10.1103/PhysRevPhysEducRes.16.023102

\section{INTRODUCTION}

School districts throughout the world face the challenge of recruiting high-quality physics teachers to teach in lowsocioeconomic status (SES) schools, where the residents' education, income, and occupation are below the average level. Meeting this challenge is essential for ensuring equal opportunities for low-SES students that respond to policy directives that call for "every student succeeds" [1]. However, teacher education graduates are generally unwilling to work in low-SES areas due to financial, geographic, living, and emotional concerns [2]. Moreover, teacher turnover rates in low-SES schools can be as high as $80 \%$ within the first three career years [3]. Even when monetary incentives, professional promotion, alternative routes, teacher rotation, and free teacher education are used in almost every country as incentives [4], challenges are troublesome, especially given the predicted rise in science, technology, engineering, and mathematics (STEM) teacher shortages. It is reported that by 2020 , the U.S., for example,

\footnotetext{
*Corresponding author. Xiaoming.zhai@uga.edu

Published by the American Physical Society under the terms of the Creative Commons Attribution 4.0 International license. Further distribution of this work must maintain attribution to the author(s) and the published article's title, journal citation, and DOI.
}

will need approximately 300000 new teachers per year, and if large numbers of teachers are not hired, the U.S. will face a severe teacher shortage that will be particularly pronounced in STEM in low-SES areas [5]. Projected teacher shortages are putting at risk not only physics education but also social equity in these communities worldwide. Filling this shortfall of high-quality physics teachers is a central challenge facing school systems throughout the world.

In this study, we examined a program launched in China specifically for preparing teachers to serve low-SES communities located in rural areas. We discussed the takeaways from this program for other nations based on the findings.

\section{A. Potential solution: Chinese carrot and stick policy}

China, the largest developing country, faces an even greater challenge of recruiting physics teachers for its lowSES communities located in rural areas. China had more than 35000000 primary and secondary students living in low-SES rural areas in the year 2018 [6]. Approximately $80 \%$ of its population is under the age of 12 . China is the country with the greatest demand for physics teachers [7]. Adding to the problem is that most college graduates increasingly prefer to work in developed urban areas rather than in low-SES rural areas. Various policies in China prevent teachers from transferring between schools. These policies exacerbate the crisis of teacher shortage because 
teacher candidates seldom desire to work in low-SES rural schools without an opportunity to transfer to advanced areas [8]. Traditional teacher recruiting strategies, used in other countries, have contributed little to China's shortage of teachers in low-SES rural schools [9].

Given this concern, China launched a governmentcontracted preservice teacher (GPT) program in 2007. High-performance secondary-school graduates are recruited through the national college entrance examination to a four-year program hosted in six top teacher education universities. They are provided with free education, stipends (approximately $¥ 9000$ per year), and promised positions after graduation [9]. In return, the participants sign a contract with the government in which they promise to work in primary or secondary schools for at least 10 years, with at least the first two years in low-SES rural schools. Participants who fail to fulfill the commitment need to compensate for the program cost, pay a penalty, and accept a poor credit rating.

Different from programs in other countries [9], the GPT program adopts multiple strategies and applies a compelling contract to ensure that participants complete the training and serve in low-SES rural areas. The GPT program thus is called a "carrot and stick" policy [10]. According to a recent report [11], through 2017, the carrot and stick policy has recruited 101000 participants from all academic areas with more than $90 \%$ of graduates having taught in low-SES rural schools.

\section{METHODS}

To assess how the Chinese GPT policy motivated students to choose this option, we recruited $n=121$ physics teachers who graduated from this program from six different cohorts (see Table I). Based on the expectancyvalue theory [12], we developed measures to examine the physics teachers' career motivation formulation and change. Specifically, we employed survey $(n=121)$, self-narrative reports $(n=121)$, group interviews $(n=38)$, and individual interviews $(n=7)$ to examine the dispositions of the teachers, the norms of the college, and the characteristics of the teachers. The survey was for description purposes that included four sections: motivation to choose the GPT program, motivation to be a physics

TABLE I. Sample information.

\begin{tabular}{lcccc}
\hline \hline $\begin{array}{l}\text { Registry } \\
\text { year }\end{array}$ & $\begin{array}{c}\text { Graduation } \\
\text { year }\end{array}$ & $\begin{array}{c}\text { No. of } \\
\text { sample }\end{array}$ & $\begin{array}{c}\text { Gender } \\
\text { (M/F) }\end{array}$ & $\begin{array}{c}\text { Working experience } \\
\text { (years) }\end{array}$ \\
\hline 2007 & 2011 & 33 & $19 / 4$ & 6 \\
2009 & 2013 & 13 & $5 / 8$ & 4 \\
2010 & 2014 & 5 & $3 / 2$ & 3 \\
2011 & 2015 & 33 & $17 / 16$ & 2 \\
2012 & 2016 & 24 & $11 / 13$ & 1 \\
2013 & 2017 & 13 & $6 / 7$ & 0 \\
\hline \hline
\end{tabular}

teacher, motivation to be working in low-SES rural schools, and motivation to be a low-SES rural physics teacher. The self-narrative reports and the interviews served to uncover the underlying mechanisms of the motivation formulation and change. We employed mixed methods to analyze how the participants formulate their motivation in the four-year program. Findings from one measure were triangulated by other measures. Specifically, we applied repeated-measures analysis of variance to examine participants' motivation change across the four years and then conducted a latent class analysis to examine the patterns of participants' dispositions of shaping their motivation to serve lowSES rural schools. Qualitative analyses of participants' narrative and interviews were used to uncover the accountability of how the policy and the program training play a role in the formulation of participants' motivation (see Methods in Supplemental Material [13]).

\section{A. Preservice physics teacher career motivation shaping}

Multivariate analyses revealed that more than $80 \%$ of the preservice teachers entered this program with extrinsic motivation $(M=2.74, \mathrm{SD}=1.24)$ to teach in low-SES rural schools. This extrinsic motivation, in combination with other factors, soon showed a negative effect on preservice teachers' attitudes toward the program. After a year of subject-matter learning, most preservice teachers reported that their motivation to teach in low-SES rural schools decreased significantly $(M=2.47, \mathrm{SD}=1.29$, $p<0.001$ ), and some believed that their decision to enter the program was imprudent. Qualitative data analysis revealed factors that account for the drop of motivation: a broad range of career interests was stirred up by social interactions with college teachers and peers and students' outcome expectation and self-efficacy was negatively impacted by the challenging subject-matter courses and college teachers' teaching styles that were significantly different from their high school teachers. This crisis led to an action to revamp and consider a new complex motivation-reshaping process, during which preservice teachers' motivation increased gradually (see Fig. 1, green line).

Using a latent class analysis on the motivation-reshaping process, we found that the preservice teachers' motivation shows four patterns (Fig. 1). The program is especially effective in improving the cluster $1(41.7 \%)$ and cluster 3 (20.3\%) preservice teachers' motivation. Though both experienced a drop of motivation after the first-year learning, indicating their vacillating inspiration, cluster 1 skipped the medium cutoff 3.0 [(not sure), $p<.005]$ and cluster 3 skipped the cutoff 4.0 [(somewhat want), $p<.001$ ] eventually. Interview data show that even though preservice teachers experienced serious doubts about whether they should enter into the program, the penalty for leaving and compensation to attend the university, they self-regulated their motivation and successfully moved 


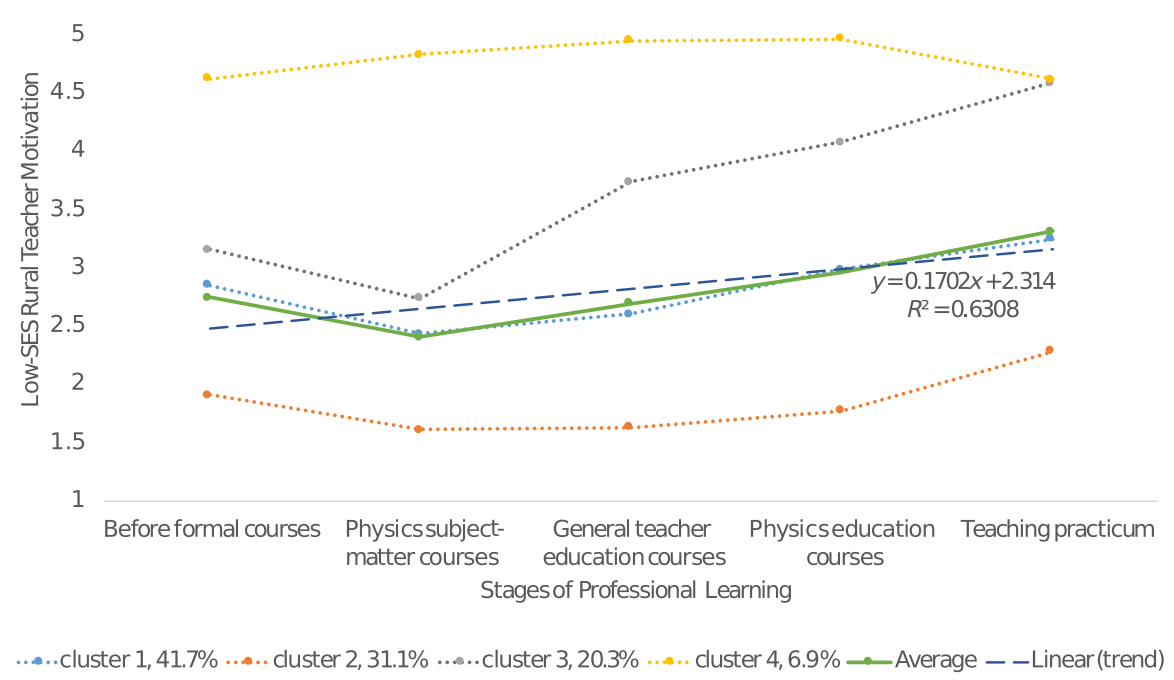

FIG. 1. Preservice physics teacher motivation change across the GPT program. The meanings of the numbers in the vertical axis are as follows: 1 , strongly do not want; 2 , somewhat do not want; 3 , not sure; 4 , somewhat want; 5 , strongly want.

toward altruistic motivation. In particular, the physics education courses and practicum helped them reignite their self-efficacy and interest. In contrast, the program did not effectively motivate the preservice teachers (cluster 2, $31.1 \%$ ) who initially did not want to be a rural teacher. According to qualitative data, these students passively entered the program through social persuasion.

By further analyzing the preservice teachers' motivationshaping process, we found, first, that the carrot and stick policy overall has a positive effect (Fig. 1, dashed line) on increasing $62.0 \%$ of preservice teachers' motivation from "not sure" to "somewhat want" or "strongly want" to be rural physics teachers, with altruistic motivation. The explicit curriculum around physics subject matter, general education, physics education, and the practicum that deliberately follows a sequence was found to have helped these participants shape their identity, increase their ability to teach and value working in low-SES rural schools, and transition from a secondary-school graduate to a preservice physics teacher. Although the contract helped most preservice teachers eliminate their reluctance to teach in low-SES rural schools, we are concerned about cluster 2 preservice teachers who, after the program, still "somewhat don't want" to be low-SES rural teachers. For these preservice teachers, the "contract" played a "negative role," since it constrained these students from quitting the program. As student 29 stated, "I got an offer for a Ph.D. program from a university abroad majoring in physics, but I just could not make it due to the constraint of the contract." Student 29 had no choice but to enter an unwanted career. How do those preservice teachers such as student 29 fare when they start with an "unwanted" position in their career life? More importantly, there is no option for preservice teachers to leave the program, which means they must complete 10 years of teaching with the first two years in low-SES rural schools or face serious consequences.

\section{B. Policy adjustment}

Being aware of these and other problems, the Department of Education in China [14] recently adjusted the policy to eliminate the negative effect, including (a) shortening the 10-year contracted teaching requirement to six-year teaching, with at least one year in low-SES rural schools and (b) allowing the preservice teachers to leave the program by the end of the first year of the program, providing the recipient repays the scholarship.

\section{Takeaways for the U.S. and other nations}

Compared to popular programs in other countries (see Supplemental Material [13]) such as Teach for America in the U.S., the GPT program has leverage because the "stick policy" required a 10-year commitment after graduation. The leverage was evidenced by more than $90 \%$ of the graduates who committed their contracts in the past for more than 10 years. In contrast, the negative effect such as that on the cluster 2 preservice teachers who found no exit option even though their motivation to serve low-SES schools was low when graduating should be strategically minimized and avoided. What can other nations learn from the carrot and stick policy to resolve the persistent problem in their physics teacher education?

First, carefully designed teacher education programs are essential for preservice teachers to shape their identity and motivation to teach in low-SES communities. Physics identity was found to be a significant predictor of students' career choice in the prior study [15]. Teachers serving lowSES communities require an identity with a more complex sociocultural obligation. They need to have enthusiasm not only for physics teaching but also for serving a dynamic cultural community with additional challenges to overcome. Overuse of the "carrot policy" might temporarily recruit a large number of participants but will cause 
problems if participants have very low intrinsic motivation. The problems are further complicated by preservice teachers' career expectations and external factors such as the GPT contract that is too lucrative to leave or reimburse yet is often in conflict with preservice teachers' intrinsic motivation. However, the data indicate that some of the preservice teachers, as a result of their four-year education program, increase their motivation to teach in low-SES communities over time.

Second, though the carrot policy attracts participants, to bring all the internal and external factors into consideration and improve preservice teachers' motivation requires an adapted curriculum that requires a focus on working with children from low-SES communities. In addition to the adapted curriculum, long-term professional learning that bridges preservice and in-service experiences is needed. The curriculum, including but not limited to physics subject-matter courses, educational courses, and practicum, benefits the development of teacher competency and selfefficacy. Specifically, the practicum is particularly useful to help teachers improve their self-efficacy, which is consistent with prior findings in Gray et al. [16]. Among those practical experiences in teaching, as suggested by Nivalainen et al. [17], preservice teachers' positive experiences with explicit objectives, high motivation, defined phenomena, and opportunity to learn to observe and report student learning are especially critical to their career success. However, there is no reason to expect that professional knowledge will lead preservice teachers to develop an altruistic motivation to work in low-SES schools. Policy or program executives thus have to pay attention to solicited curriculum targeting SES culture that has the potential to help preservice teachers identify the social value of working in low-SES areas.

Third, the stick policy should be used strategically and cautiously in other nations. The stick policy is particularly useful to keep participants from pursuing other career tracks and to keep them on track when they experience imbalance or ambivalence with regard to serving low-SES schools. At the same time, this stick policy has drawn criticism because at least a proportion of the participants who did not significantly increase their motivation at the end of the program would have to enter a career that they did not like due to the policy. Thus, for those preservice teachers who find that they have no enthusiasm to serve as a physics teacher in low-SES schools after entering the program, a reasonable exit option ought to be provided.
Fourth, professional guidelines for career selection in all nations should always be provided both before and during teacher preparation programs to avoid the "carrot-overuse" effect and keep the participants from ambivalence regarding career motivation. Zhai's [18] results suggest that the nature of the motivation change is a feeling of ambivalence (e.g., imbalance of task demand and return) in pursuing a career in low-SES areas. To avoid such ambivalence, the participants should have sufficient professional knowledge regarding the nature of the career even before they enter the program. For example, a one- or two-week career consulting service can be valuable to guide these participants. The knowledge possibly gained through professional guides could also help to decrease the effect of overuse of the carrot policy on participants' selection of the program. Also, we suggest that guidance should be provided, or interventions should be developed, to help preservice teachers strategically get back on track if they feel imbalance or ambivalence during the program.

Last, we call for more studies investigating preservice physics teachers' motivation-shaping process for programs such as GPT and what can be done to attract and retain high caliber physics teachers to work in low-SES rural environments. Particularly, attention should be paid to cultural factors, gender differences, equity, policy, etc. Though recruiting high-quality physics teachers for the low-SES community is critical to equity and social justice, this need has rarely been met worldwide [18]. Very limited studies have dedicated effort to study policies or programs that may improve physics teachers' dispositions to serve students in low-SES schools. A better understanding of the mechanisms of preservice physics teachers' career motivation formulation will help us balance the potential "carrot" and "stick" and develop a sound curriculum to guide their professional learning. The effectiveness of curriculum learning ensures that participants build their identity as a low-SES teacher to benefit students in low-SES schools, and helps the physics teachers themselves lead valuable and joyful lives.

\section{ACKNOWLEDGMENTS}

This research was partially supported by the John A. Hannah Chair in the College of Education at Michigan State University and the Lappan-Phillips Chair in the College of Natural Science at Michigan State University. 
[1] Every Student Succeeds Act, https://www.govtrack.us/ congress/bills/114/s1177.

[2] H. Cuervo and D. Acquaro, Exploring metropolitan university pre-service teacher motivations and barriers to teaching in rural schools, Asia-Pacific J. Teach. Educ. 46, 1 (2018).

[3] J. V. Heilig and S. J. Jez, Teach for America: A return to the evidence, https://scholar.colorado.edu/nepc/139, retrieved Sept. 29, 2019.

[4] A. Barry, National exceptional teachers for disadvantaged schools (NETDS), https://www.socialventures.com.au/ work/nationalexceptional-teachers-for-disadvantagedschools/, retrieved on Sept. 29, 2019.

[5] L. Sutcher, L. Darling-Hammond, and D. Carver-Thomas, A coming crisis in teaching? Teacher supply, demand, and shortages in the US, https://learningpolicyinstitute.org/ product/coming-crisis-teaching.

[6] Department of Education of the People's Republic of China, Public Statistical Information of Education in 2018, http://www.moe.gov.cn/s78/A03/moe_560/jytjsj_ 2018/, retrieved on Sep. 20, 2019.

[7] E. Liu, C. Liu, and J. Wang, Pre-service science teacher preparation in China: Challenges and promises, J. Sci. Teach. Educ. 26, 29 (2015).

[8] S. Liu, On staffing structure optimization of rural teachers in China, Educ. Res. 435, 81 (2016), retrieved on Sept. 29, 2019.

[9] D. Wang and M. Gao, Educational equality or social mobility: The value conflict between preservice teachers and the Free Teacher Education Program in China, Teach. Teach. Educ. 32, 66 (2013).
[10] R. Yuan and L. J. Zhang, Exploring student teachers' motivation change in initial teacher education: A Chinese perspective, Teach. Teach. Educ. 61, 142 (2017).

[11] Department of Education of the People's Republic of China, Question and answers for the free tuition policy, http://www.moe.gov.cn/jyb_xwfb/s271/201808/ t20180810_344982.html, retrieved Sept. 20, 2019.

[12] P. W. Richardson and H. M. Watt, Who chooses teaching and why? Profiling characteristics and motivations across three Australian universities, Asia-Pacific J. Teach. Educ. 34, 27 (2006).

[13] See Supplemental Material at http://link.aps.org/ supplemental/10.1103/PhysRevPhysEducRes.16.023102 for the methodology for this study.

[14] The policy of Government-supported teacher education program, http://www.moe.gov.cn/jyb_xxgk/moe_1777/ moe1778/201808/t20180810_345023.html, retrieved Sept. 29, 2019.

[15] Z. Hazari, G. Sonnert, P. M. Sadler, and M. C. Shanahan, Connecting high school physics experiences, outcome expectations, physics identity, and physics career choice: A gender study, J. Res. Sci. Teach. 47, 978 (2010).

[16] K. E. Gray, D. C. Webb, and V. K. Otero, Effects of the learning assistant model on teacher practice, Phys. Rev. Phys. Educ. Res. 12, 020126 (2016).

[17] V. Nivalainen, M. A. Asikainen, and P. E. Hirvonen, Preservice teachers' objectives and their experience of practical work, Phys. Rev. ST Phys. Educ, Res. 9, 010102 (2013).

[18] X. Zhai, Becoming a teacher in rural areas: How curriculum influences government-contracted pre-service physics teachers' motivation, Int. J. Educ. Res. 94, 77 (2019). 